Volume 16 - Número 1 - jan/jul de 2021

\title{
A LEITURA DO ESPAÇO EM POESIAS DE CECÍLIA MEIRELES: UMA ABORDAGEM BACHELARDIANA
}

\author{
READING THE SPACE IN POETRY OF CECILIA MEIRELES: A \\ BACHELARDIANA APPROACH
}

\author{
Jéssica Taiara Kottwitz ${ }^{1}$
}

\begin{abstract}
RESUMO: Este trabalho traz algumas reflexões acerca dos estudos realizados sobre a imaginação, o espaço e o devaneio, conceitos alicerçados nos trabalhos do filósofo francês Gaston Bachelard (1988; 1989), que refletem sobre a imersão do leitor nas criações literárias, entre elas, a poesia. A fim de exemplificar tais considerações, apresenta-se uma análise dos poemas "Canção da tarde no campo" e "Narrativa", presentes na obra Vaga música (1942), de Cecília Meireles. A metodologia utilizada consiste em uma pesquisa bibliográfica e análise de poemas, observando a sua relação com a criação poética e os espaços criados pela nossa imaginação. Ao encontrar os poemas, o leitor depara-se com o universo de Cecília e, ao mesmo tempo, com sua própria identidade, momento em que as palavras constituem a criação do espaço poético, da qual podem emergir inúmeras ressonâncias. Os resultados da pesquisa convergem com a ideia de que é através do poder criador da linguagem que o ser humano é capaz de recriar a si mesmo e a sua realidade, percebendo que o mundo também se apresenta como espaço que pode ser transformado. Tais afirmações evidenciam que a poesia está presente nas sutilezas do cotidiano e que um poeta é capaz de percebê-la, convertendo essa presença em palavras que são capazes de nos encantar.
\end{abstract}

PALAVRAS-CHAVE: Cecília Meireles. Devaneio. Gaston Bachelard. Poesia.

\begin{abstract}
This work brings some reflections about the studies carried out on imagination, space and reverie, concepts based on the works of the French philosopher Gaston Bachelard (1988; 1989), which reflect on the immersion of the reader in literary creations, among them, poetry. In order to exemplify these considerations, an analysis of the poems "Canção da tarde no campo" and "Narrativa", present in Vaga música (1942), by Cecília Meireles. The methodology used consists of a bibliographic research and analysis of poems, observing its relationship with poetic creation and the spaces created by our imagination. When reading the poems, the reader is faced with the universe of Cecilia and, at the same time, with his own identity, a moment when words constitute the creation of the poetic space, from which countless resonances can emerge. The results of the research converge with the idea that it is through the creative power of language that the human being is able to recreate himself and his reality, realizing that the world also presents itself as a space that can be transformed. Such statements show that poetry is present in the subtleties of everyday life and that a poet is able to understand it, converting this presence into words that are capable of delighting us.
\end{abstract}

KEYWORDS: Cecília Meireles. Daydream. Gaston Bachelard. Poetry.

\section{Introdução}

A imaginação é uma das capacidades de nós, humanos, encontrarmos maneiras de habitarmos o mundo. Levando-se em conta que, podendo imaginar, também somos capazes de pensar além de nossa própria vida, fazemos isso através da linguagem, seja ela visual, gestual ou/e, principalmente, de maneira verbal, através de e com palavras. Sendo as palavras tão presentes no cotidiano e a sua ausência ser quase que inimaginável, pensamos e expressamos com elas as inúmeras imagens que compõem nossas ideias/sonhos/devaneios.

Não buscando explorar em demasia tais aspectos, mas concentrando nosso interesse na imaginação e de que forma essa faculdade pode ampliar a nossa condição de seres que podem devanear outros tempos e lugares, propomos entender os conceitos de Gaston Bachelard, vinculados à poética, para, depois, aliando-os à poesia, compor o entendimento de que a

\footnotetext{
${ }^{1}$ Mestra em Letras/Leitura e Cognição pela Universidade de Santa Cruz do Sul - UNISC e graduada em Letras/Português pela mesma instituição. ORCID: https://orcid.org/0000-0003-2973-5046. E-mail: jessicakottwitz@gmail.com
} 
Volume 16 - Número 1 - jan/jul de 2021

linguagem pode estar diretamente relacionada a cenários ficcionais, seja por meio de uma lembrança, de um verso ou, mesmo, de uma única palavra que esteja florescendo em seu sentido puro e poético.

Sendo assim, este estudo tem como metodologia a pesquisa bibliográfica, na qual se apresentam atrelados os poemas de Cecília Meireles, que serão analisados tendo como base os estudos do filósofo francês Gaston Bachelard, a fim de exemplificar a questão dos espaços imagéticos para o leitor.

Iniciamos com uma reflexão sobre o conceito de espaço, buscando explicar como as imagens relacionadas a esse conceito estão sempre presentes, já que podemos habitar espaços reais e lembrarmos de espaços que nos são importantes, da mesma forma que podemos devanear espaços que não existem de forma concreta. Após o estudo teórico que se apresenta a seguir, encontra-se a análise dos poemas de Cecília Meireles, seguida das considerações e resultados acerca do presente trabalho.

\section{0 espaço poético da imaginação}

Refletir sobre a poética dos espaços implica pensarmos na existência de um lugar real, concreto, ou um espaço imaginado, para o qual direcionamos a construção de um espaço ficcional. Não que o espaço ficcional não possa acontecer realisticamente. O espaço poético tem a ver com essa possibilidade de constituir outros espaços que não os que podemos enxergar com nossos olhos. O espaço ficcional liga-se ao poético quando, encontrando o rumo a ser seguido, ele se forma e se transforma e, também, se deforma, ampliando a ideia que se tinha ou se tem de tal paisagem. Por isso, a ideia de uma paisagem pode ser explorada por uma ótica inversa, como, no caso, da poesia, em que lemos com o ouvido e somos capazes de ver com a atenção de nossa escuta uma nova paisagem, a imagem.

Gaston Bachelard (1988, p. 44) acredita que o devaneio surge das forças vivas da linguagem, no qual a imagem poética tem uma dinamicidade própria. Analisando diversas obras poéticas, o filósofo demonstra a vivacidade da imaginação que, no movimento do sentido, eleva o espírito do leitor/ouvinte e pode direcioná-lo no caminho da imaginação criadora, que potencializa a repercussão e as ressonâncias:

É depois da repercussão que podemos experimentar ressonâncias, repercussões sentimentais, recordações do nosso passado. Mas a imagem atingiu as profundezas antes de emocionar a superfície. E isso é verdade numa simples experiência de leitura. Essa imagem que a leitura do poema nos oferece torna-se realmente nossa. Enraíza-se em nós mesmos. Nós a recebemos, mas sentimos a impressão de que teríamos podido criá-la, de que deveríamos tê-la criado. A imagem torna-se um ser novo da nossa linguagem, expressa-nos tornando-nos aquilo que ela expressa - noutras palavras, ela é ao mesmo tempo um devir de expressão e um devir do nosso ser. Aqui, a expressão cria o ser. (BACHELARD, 1989, p. 7-8)

O aprofundamento da existência, bem como as recordações mais puras podem ser envolvidas pelo par repercussão/ressonâncias. Com esses fenômenos, é possível buscar a compreensão da emoção que toma conta do leitor de poemas, aproximando-o do ato criador do poeta.

Para tanto, a formação de um espaço, em um sentido subjetivamente vinculado à imaginação, pode surpreender o leitor, aproximando-o de sua própria identidade e do lugar em que vive ou já viveu. Como propõe Bachelard (1989, p. 31), “o espaço convida à ação, e antes 
Volume 16 - Número 1 - jan/jul de 2021

da ação a imaginação trabalha". O espaço poético é, então, a abertura para o mundo da beleza e do sonho: "para o meu eu sonhador, é esse não-eu meu que me permite viver minha confiança de estar no mundo" (BACHELARD, 1988, p. 13, grifo do autor).

A imagem de um poema pode revelar inúmeros aspectos de uma vida. Como colocado por Paz (1982, p. 29), “cada leitor procura algo no poema. E não é insólito que o encontre: já o trazia dentro de si". Por isso, aquilo que salta aos olhos do leitor pode ser o que mais lhe causa emoção, encantamento ou afeto, a poesia "nos dá uma impressão de juventude ou de rejuvenescimento ao nos restituir ininterruptamente a faculdade de nos maravilharmos. A verdadeira poesia é uma função de despertar" (BACHELARD, 1989, p. 18), função essa que é capaz de trazer à superfície as camadas mais importantes da vida, entre elas, os espaços que são caros à história de cada ser humano.

A afirmação bachelardiana que diz que "a palavra de um poeta, tocando o ponto exato, abala as camadas profundas do nosso ser" (BACHELARD, 1989, p. 32) compreende uma afetação, na qual existe um leitor/ouvinte atento e repousando em suas imagens poéticas, na certeza de nelas encontrar um refúgio, um caminho, uma solução ou, mesmo, o insolúvel enigma que contorna a existência humana, já que um poema "não diz o que é e sim o que poderia ser" (PAZ, 1982, p. 120).

Os lugares que nossa memória guarda são uma espécie de reserva, reserva que se altera quando nos deparamos com novas possibilidades de viver, tanto que Bachelard (1989, p. 131) chegou a pensar que "a imaginação é anterior à memória". Esses espaços podem se expandir ou até desaparecem, quando não damos mais a atenção necessária a sua permanência.

A referência aos termos espaço e lugar é utilizada, nesta escrita, como sinônima, porém, se ampliarmos o estudo sobre essas palavras, encontraremos, também, possíveis diferenças entre elas. Certeau (2001, p. 201) é um dos estudiosos que distinguiu as palavras espaço e lugar. O lugar, neste caso, tem a ver com a estabilidade das posições, é a ordem de distribuição de elementos que estão relacionados ao cotidiano. Em complementação,

o espaço é um lugar praticado. Assim a rua geometricamente definida por um urbanismo é transformada em espaço pelos pedestres. Do mesmo modo, a leitura é o espaço produzido pela prática do lugar constituído por um sistema de signos - um escrito. (CERTEAU, 2001, p. 202, grifos do autor)

Essas diferenças comprovam que não há espaço sem movimentação de pessoas. O que há são lugares desprovidos de ocupação. Carlos (1996, p. 23) usa a palavra lugar para se referir ao vivido e ao imediato. Neste contexto, o lugar é "o que pode ser apropriado pelo corpo". O autor vê na metrópole lugares que, por não serem utilizados, são vazios de sentido para as pessoas. Sendo assim, sujeito e lugar se pertencem e a produção do ambiente é também a produção da vida (CARLOS, 1996, p. 29). Refletir sobre o espaço também é analisar o vivido, a partir dos ritmos que cada coletividade institui e das formas como se apropria dos lugares. Mais uma vez temos a afirmação da presença humana na constituição de uma valoração do espaço.

O tempo se encarrega de mudanças que podem refletir tanto nas nossas ações como nos espaços que habitamos. Conforme Santos (1999, p. 83), "o espaço é sempre um Presente, uma construção horizontal, uma situação única". Um espaço que não é contemporâneo não pode ser frequentado e também não pode ser alterado. A afirmação de Santos corrobora com a ideia de Tuan (1983, p. 18), para quem "os espaços do homem refletem a qualidade dos seus sentidos e sua mentalidade". A singularidade dos acontecimentos está particularmente associada ao momento em que se vive em determinado lugar e só assim se poderá descrever esse espaço como ele é, no tempo presente. 
Volume 16 - Número 1 - jan/jul de 2021

Assim como pode haver distinção entre espaço e lugar, a paisagem e o espaço também não são sinônimos, para Santos $(1999$, p. 83). O autor entende que a paisagem compreende o conjunto de formas que expressam as relações entre humano e natureza. Já os espaços são as formas e a vida que as ocupa. Para explicitar essa diferença, ele desenvolve a ideia de evento, a movimentação de pessoas nos locais: "os eventos são, pois, todos novos. Quando eles emergem, também estão propondo uma nova história. Não há escapatória" (SANTOS, 1999, p. 116).

Da mesma forma, Ricoeur (2007, p. 157) pondera o entendimento de que todo ser humano busca o pertencimento, seja de um lugar ou de um grupo: "meu lugar é ali onde está meu corpo. Mas colocar-se e deslocar-se são atividades primordiais que fazem do lugar algo a ser buscado". Por isso, mesmo quando o ser humano se separa de sua morada natal, continua a lembrar dela como a morada que esconde seus primeiros sonhos, é um espaço primitivo de sua existência.

Outro pensador das relações de visibilidade é o geógrafo Paulo Gomes (2013), que vê os espaços como produtores de sentido somente no momento em que são ocupados. A visibilidade desses espaços, conforme o autor, depende de três elementos:

das leituras do sentido que emergem da associação entre o lugar e o evento, ou ainda, da significação que nasce da posição dentro de um contexto espacial no qual se inscreve o fenômeno. Em seguida, dependerão também da possibilidade da morfologia do espaço físico onde se mostra e que deve ser capaz de garantir uma convergência dos olhares e a desejada captura da atenção. Finalmente, o terceiro elemento é que esse lugar deve garantir a presença de observadores sensíveis aos novos sentidos nascidos da associação entre o lugar e o evento que se apresenta. (GOMES, 2013, p. 37-38)

Pelos elementos elencados acima, alguns lugares são mais valorizados porque concentram significações, ganhando centralidade no imaginário social e a busca de eventos pode trazer à tona fatos ainda não presenciados pela sensibilidade do olhar. Essas diferenciações, apesar de não serem o foco principal deste estudo, são importantes na medida em que demonstram que nós temos um senso de pertencimento que engloba não só o fato de ocuparmos espaços, mas também de sermos produtores de sentido a partir desse lugar que falamos e/ou vivemos. Seguiremos, por isso, centrando nossa atenção ao espaço enquanto parte importante da nossa vida, elemento que nos constitui na medida em que é constituído pela presença do homem.

A imaginação, na maioria das vezes, procura as imagens da alegria, imagens que possam sustentar as reservas de entusiasmo que favorecem o porvir das coisas, das sensações, "no sentido de um porvir da superfície" (BACHELARD, 1997, p. 2). Por isso, o filósofo francês acredita que, ao falar, a pessoa traz em sua voz as ressonâncias de seus espaços sonhados, amados, vividos: "Toda pessoa deveria então falar de suas estradas, de suas encruzilhadas, de seus bancos. Toda pessoa deveria fazer o cadastro de seus campos perdidos" (BACHELARD, 1989, p. 31).

Tendo em vista todos os aspectos que podem surgir diante de uma situação em que o leitor encontra no poema parte de sua alma ou de sua imaginação criadora, é possível buscar espaços que são importantes ou que ainda podem emergir a partir de elementos, palavras, versos e imagens que compõem a criação poética, levando-se em conta que o leitor de poemas também é um criador. Ao fazer isso, pode-se ter a evidência do quanto estamos intimamente relacionados aos espaços, sejam eles inventados e/ou reais. 
Volume 16 - Número 1 - jan/jul de 2021

\section{Imagens na poesia de Cecília Meireles}

A poesia de Cecília Meireles merece destaque em relação a toda a sua obra, já que, desde muito cedo, a escritora dedicou sua vida à escrita de inúmeros poemas que podem ser apreciados tanto pelos leitores iniciantes até pelos mais vividos, para os quais a leitura de seus textos pode ser encarada como uma forma de recordar toda a sua obra poética, a "estrela" de sua vida inteira.

A poeta Cecília Meireles, que nasceu e faleceu no Rio de Janeiro, publicou seu primeiro livro de poemas com 18 anos, talento que a tornou autora de inúmeras obras, sendo Vasta música uma delas. Além de escritora, vale destacar que Cecília Meireles também foi professora e recebeu muitos prêmios.

Objetivando tecer comparações entre sua criação e a relação com o espaço poético, foram escolhidos os poemas "Canção da tarde no campo" e "Narrativa", que se encontram na obra Vaga música, de 1942, na qual Cecília Meireles deixou um conjunto de poemas marcantes, caracterizados pela lírica e pela musicalidade que há na arte de viver. As palavras trazem essa delicada tonalidade de cores, sons e imagens, presentes, inclusive, no primeiro poema escolhido (MEIRELES, 1983, p. 186):

\section{CANÇÃO DA TARDE NO CAMPO}

CAMINHO do campo verde, estrada depois de estrada. Cercas de flores, palmeiras, serra azul, água calada.

(Eu ando sozinha no meio do vale. Mas a tarde é minha.)

Meus pés vão pisando a terra que é a imagem da minha vida: tão vazia, mas tão bela, tão certa, mas tão perdida!

(Eu ando sozinha por cima de pedras. Mas a flor é minha.)

Os meus passos no caminho são como os passos da lua: vou chegando, vais fugindo, minha alma é a sombra da tua.

(Eu ando sozinha por dentro de bosques. Mas a fonte é minha.)

De tanto olhar para longe, não vejo o que passa perto. Subo monte, desço monte, meu peito é puro deserto.

(Eu ando sozinha 
Volume 16 - Número 1 - jan/jul de 2021

ao longo da noite.

Mas a estrela é minha.)

Visualizando o poema, já em um primeiro momento, percebe-se sua estrutura bem marcada por estrofes ora de quatro, ora de três versos. Essa peculiaridade demonstra que estamos diante de uma construção poética com repetições, porém são repetições que oscilam entre a estrutura e as demais possibilidades apresentadas pela poeta.

$\mathrm{Na}$ primeira estrofe, o eu lírico apresenta uma enumeração de elementos que se encontram por um suposto caminho: campo verde, outras estradas, cerca de flores, palmeiras, a serra, caracterizada como azul e, por último, a água, que recebe o adjetivo de calada, ou seja, parada, sem movimento. Diante de cada um desses elementos naturais, podemos vislumbrar uma paisagem tranquila, que traduz uma mensagem de paz e de calmaria.

Dando continuidade, na segunda estrofe, encontra-se uma espécie de revelação (colocada entre parênteses) que aprimora a noção de paisagem vislumbrada: o eu lírico está sozinho e revela uma espécie de satisfação ao tomar a tarde como posse sua, da mesma forma que fará nas estrofes 4, 6 e 8, com a flor, a fonte e a estrela. Tais elementos soam como uma recompensa em relação ao fato de o eu lírico estar sozinho, pois o uso da conjunção "mas" traz essa alteridade à construção dos versos que, ao se repetirem, mesmo não possuindo toda a semelhança, estão dispostos de modo que possam indicar um sentido parecido, do início ao fim.

A terceira estrofe evidencia o toque dos pés na terra, que simbolicamente é apresentada como "vazia" e "certa", o que dá a ideia de concretude e certeza, características que se opõem, porém, a sua beleza e perdição. A terra é, para o eu lírico o elemento que representa a sua vida, mas, que pode, também, representar a finitude.

Os passos sobre a terra são comparados, na quinta estrofe, com pegadas na lua, que chegam e fogem, como sombras que se estendem a alguém: "minha alma é a sombra da tua.", ou seja, o eu lírico se aproxima do leitor na sua condição humana e seus passos podem ser também os passos de outros seres humanos, que caminham sobre a terra e a lua, ambas circulares, como em um ciclo que se encerra e recomeça, como a vida, em suas diferentes fases.

A sexta estrofe traz o eu lírico como alguém que está sempre olhando além de sua vida, "De tanto olhar para longe,/não vejo o que passa perto.", dando a impressão de que não está pensando no presente, mas caminhando em direção ao futuro. Esse caminhar, de subir e descer montes, pode indicar os obstáculos e as inúmeras incertezas de viver, mas também suas vitórias e prazeres. Se o peito do eu lírico é puro deserto, pode estar vinculado a essa vontade de desbravar caminhos, não deixar de caminhar, seguir em frente e ver as belezas que a vida pode colocar nessa estrada, seja ela o próprio deserto ou o simples e calmo campo.

A última estrofe, novamente, denota a figura de uma pessoa solitária, mas que sabe fazer proveito dessa situação. O poema, contemplado em sua totalidade, traz a construção da solidão de uma maneira que, mesmo mostrando suas características mais puras, também apresenta o lado precioso de se saber contemplar a caminhada. A visão de espaço observada no poema pode lembrar de momentos relacionados à solidão e essa é uma das possibilidades de poder devanear sem interrupções. A concha, para Bachelard, é um elemento que representa o sentido de habitar em sua forma mais pura, de aconchego e proteção, tanto que ele afirma: "sabemos bem que é preciso estar só para habitar uma concha. Vivendo a imagem, sabemos que aceitamos a solidão" (BACHELARD, 1989, 134).

$\mathrm{Na}$ certeza de haver outras interpretações para o poema de Cecília Meireles, entendemos que essa foi somente uma das maneiras de apresentá-lo a fim de iluminar os versos da poeta, relacionando-os à temática que escolhemos tratar nesse artigo. Em palavras de Bachelard (1989, p. 68), os espaços que amamos "se desdobram. Parece que se transportam facilmente para outros lugares, para outros tempos, para planos diferentes de sonhos e lembranças". O espaço do campo é, inicialmente, visto como aparece em sua realidade, um local calmo e silencioso. 
No decorrer do poema, os passos do eu lírico encontram os devaneios que podem estar relacionados ao elemento terra e convidam o leitor a uma caminhada pelo longo caminho do campo, que parece um deserto de tão infinito e/ou a lua solitária, incapaz de oferecer abrigo ao homem, sendo, somente, um lugar de passagem. Porém, na visão do eu lírico, pode ser, também, um espaço de muita beleza e realização.

A terra e a lua, em seu formato redondo, lembram, também, o acolhimento, o eu-lírico tem a liberdade de caminhar nessas superfícies, tão idênticas, exceto o fato de a lua ser mais solitária que a terra, em termos de habitação. Na concepção bachelardiana, "as imagens da redondeza plena ajudam a nos congregarmos em nós mesmos, a darmos a nós mesmos uma primeira constituição, a afirmar o nosso ser intimamente, pelo interior" (BACHELARD, 1989, p. 237). O poema de Cecília traz essa sensação de circularidade, seja pela sua estrutura, na qual há repetição de estrofes, seja pela imagem poética de caminhar incansavelmente ao redor. Para o eu-lírico do poema, é possível realizar o inimaginável, pois a poesia tem essa viabilidade vantajosa.

O outro poema a ser analisado chama-se "Narrativa" e também pertence à coletânea Vaga música (MEIRELES, 1983, p. 209):

\author{
NARRATIVA \\ ANDEI BUSCANDO esse dia \\ pelos humildes caminhos \\ onde se escondem as coisas \\ que trazem felicidade: \\ os amuletos dos grilos \\ e os trevos de quatro folhas... \\ Só achei flor de saudade. \\ O arroio levava o tempo. \\ Ia meu sonho atrás da água. \\ No chão dormiam abertas \\ minhas duas mãos sem nada. \\ Se me chamavam de longe, \\ se me chamavam de perto, \\ era perdida, a chamada... \\ Viajei pelas estrelas \\ dentro da rosa-dos-ventos. \\ Trouxe prata em meus cabelos, \\ pólen da noite sombria... \\ Mirei no meu coração, \\ vi os outros, vi meu sonho, \\ encontrei o que queria. \\ Já não mais desejo andanças; \\ tenho meu campo sereno, \\ com aquela felicidade \\ que em toda parte buscava. \\ O tempo fez-me paciente. \\ A lua, triste mas doce. \\ O mar, profunda, erma e brava.
}


Volume 16 - Número 1 - jan/jul de 2021

O poema "Narrativa" pode ser considerado muito semelhante ao poema anterior, porque possui, novamente, em sua estrutura, elementos que são a chave para os devaneios que se encontram nos versos. A saudade mais uma vez é lembrada como uma espécie de oposição às coisas que trazem felicidade, porém, é um sentimento que se faz importante no contexto do poema. Um arroio que levava o tempo traz a água como elemento necessário que dilui as recordações. $\mathrm{O}$ eu lírico se encontra como que perdido em seu próprio sonho. A noite, com a lua e as estrelas, são a moldura dos versos, que, ao contrário do poema anterior, que tinha a caminhada como desfecho, conduzem o leitor ao repouso do campo.

$\mathrm{O}$ eu lírico, na terceira estrofe, afirma que viajou pelas estrelas, uma viagem que pode ser entendida como um sonho ou como um devaneio. Essa diferença pode ser uma das possíveis maneiras de chegarmos ao "coração" desse poema, pois, se pensado no viés do sonho, encontramos seus versos imersos na confusa escuridão da noite e, se o tomarmos como um devaneio, encontramos um eu lírico que, mesmo tendo sonhado, encontra no sonho motivos para dar mais sentidos a sua existência.

$\mathrm{Na}$ última estrofe, os versos "O tempo fez-me paciente./A lua, triste mas doce./O mar, profunda, erma e brava." trazem o antagonismo também presente no poema "Canção da tarde no campo". Bachelard (1990a; 1990b; 1991; 1997; 1999) já explorava os quatro elementos de Empédocles, a terra, a água, o ar e o fogo. A água tem, para o filósofo, essa característica dual, de ser calma e/ou mais agitada, sendo, portanto, um elemento que envolve a vibração entre anima e animus, a pureza e a cólera: "A água é uma matéria que vemos nascer e crescer em toda parte. A fonte é um nascimento irresistível, um nascimento contínuo" (BACHELARD, 1997, p. 15).

Em linhas gerais, o poema traz nos versos a narrativa de um eu lírico que, buscando encontrar sua felicidade, entende que o seu desejo de não mais andar, tornaria sua vida mais proveitosa e tranquila, apesar das recordações que a água levou, a noite trouxe as respostas que eram desejadas. O próprio título do poema traz a noção de contar ou narrar algo, ideia que pode persuadir o leitor a buscar no texto alguma semelhança com a narração, ou seja, um possível enredo, com personagem, espaço, tempo etc. Porém, tal evidência pode ser ignorada e a leitura do poema pode seguir seu percurso original, de ser lido e apreciado como é, poesia.

A identificação do leitor com o espaço contemplado nos dois poemas transcritos evidencia a importância dessa correspondência para que devaneios relacionados à vida possam compor esses cenários, que, apesar de mudarem, continuam sendo parte de nossas narrativas pessoais, em que sempre haverá uma referência ao tempo e ao espaço em que aconteceram. Mais uma vez retomamos Bachelard (1989, p. 19), que acredita que um espaço imaginado não pode ser indiferente, pois não deixa de ser vivido, mesmo que somente imaginado. Nesse caso, a poesia existe para que as pessoas possam admirar com lentes diversas as pequenas coisas/sensações/situações da vida.

\section{Considerações finais}

O filósofo francês Gaston Bachelard, o qual foi referenciado no trabalho por inúmeras vezes, afirmou: "serei um habitante do mundo, apesar do mundo" (BACHELARD, 1989, p. 62). Habitar o mundo implica habitar as possibilidades de viver em diferentes espaços, transitar por lugares conhecidos e desconhecidos, espaços que os olhos veem e, também, aqueles que somente nossa alma é capaz de escutar e conhecer.

Os dois poemas que foram analisados trazem como principais características os devaneios do eu lírico com a saudade, o espaço, demarcado pelo campo, elementos como a água, o ar e a terra, a noite, a incerteza entre ficar e partir. Inúmeras são as veredas por onde o 
Volume 16 - Número 1 - jan/jul de 2021

pensamento pode se perder, então, seja na proteção da casa ou nas estradas do exterior, a busca por alguma coisa é o que caracteriza a vontade de ação, como afirma Bachelard (1989, p. 148), "a seriedade da vida está no exterior".

Como pode-se notar, são temas abrangentes que envolvem a dinamicidade da vida em suas inúmeras camadas. Longe de alcançarmos interpretações universais, a poesia de Cecília Meireles pode ser lida e compreendida de diversas formas, pois a profundidade de suas palavras atinge a alma dos leitores, fazendo com que se sintam tão criadores quanto a própria poeta.

Os poemas de Cecília demonstram que o tempo e o espaço constituem valores diferentes para nós, valores que se diluem em determinadas "estações" para retornarem com mais intensidade em outras. Fazendo essa análise, é possível compartilhar dos sentimentos que as palavras de cada verso emitem e que provocam repercussões distintas, porém verdadeiras em cada imagem singular que as encontra.

É através da imaginação que podemos viver um espaço novo. Muitos espaços podem ser conhecidos apenas na leitura, os espaços ficcionais, imaginados, que podem revelar as características da grandeza e daquilo que é pequeno, já que "a miniatura é uma das moradas da grandeza" (BACHELARD, 1989, p. 164). Outros, em sua maioria, são espaços que conhecemos desde a infância, como o lugar onde nascemos, as casas em que moramos, espaços que oscilam entre o real e o imaginado. Entendendo que as imagens do espaço podem ser bastante distintas e variarem de pessoa para pessoa, podemos pensar que "os espaços amados nem sempre querem ficar fechados! Eles se desdobram. Parece que se transportam facilmente para outros lugares, para outros tempos, para planos diferentes de sonhos e lembranças" (BACHELARD, 1989, p. 68). E assim vão se criando histórias, músicas, poesias e marcas que perduram pelo tempo, mantendo as imagens poéticas para quem quiser e souber senti-las.

\section{Referências}

BACHELARD, Gaston. A água e os sonhos: ensaio sobre a imaginação da matéria. Tradução de Antonio de Pádua Danesi. São Paulo: Martins Fontes, 1997.

BACHELARD, Gaston. A poética do devaneio. Tradução de Antonio de Pádua Danesi. São Paulo: Martins Fontes, 1988.

BACHELARD, Gaston. A poética do espaço. Tradução de Antonio de Pádua Danesi. São Paulo: Martins Fontes, 1989.

BACHELARD, Gaston. A psicanálise do fogo. Trad. Paulo Neves. 2. ed. São Paulo: Martins Fontes, 1999.

BACHELARD, Gaston. A terra e os devaneios da vontade: ensaio sobre a imaginação das forças. 1. ed. São Paulo: Martins Fontes, 1991.

BACHELARD, Gaston. A terra e os devaneios do repouso: ensaio sobre as imagens da intimidade. Tradução de Paulo Neves da Silva. 1. ed. São Paulo: Martins Fontes, 1990a.

BACHELARD, Gaston. O ar e os sonhos: ensaio sobre a imaginação do movimento. 1. ed. São Paulo: Martins Fontes, 1990b.

CERTEAU, Michel de. A invenção do cotidiano. Tradução de Ephraim Ferreira Alves. 6. ed. Petrópolis: Vozes, 2001.

CARLOS, Ana Fani Alessandri. O lugar no/do mundo. São Paulo: Hucitec, 1996.

GOMES, Paulo Cesar da Costa. O lugar do olhar: elementos para um geografia da visibilidade. Rio de Janeiro: Bertrand Brasil, 2013.

MEIRELES, Cecília. Vaga música. In: Obra poética. Rio de Janeiro: Nova Aguilar, 1983. p. $142-215$

PAZ, Octavio. O arco e a lira. Tradução de Olga Savary. Rio de Janeiro: Nova Fronteira, 1982. RICOEUR, Paul. A memória, a história, o esquecimento. Tradução de Alain François et. al. São Paulo: Unicamp, 2007. 
Volume 16 - Número 1 - jan/jul de 2021

SANTOS, Milton. A natureza do espaço: espaço e tempo: razão e emoção. 3. ed. São Paulo: Hucitec, 1999.

TUAN, Yi-Fu. Espaço e lugar: a perspectiva da experiência. Tradução de Lívia de Oliveira. São Paulo: Difel, 1983.

Submetido em 19/03/2021

Aceito em 20/08/2021 